\title{
A Mini Review on Natural Fiber Honeycomb (NFH) Sandwiched Structure Composite: Flexural Perfomance Perspective
}

\author{
Nahiyan Al-Azad, Evelynda Christy Mojutan, Mohd. Kamal Mohd. Shah* \\ Advanced Composite Research Group, Faculty of Engineering, Universiti Malaysia Sabah, Malaysia \\ Email: ^mkamalms@ums.edu.my
}

How to cite this paper: Al-Azad, N., Mojutan, E.C. and Shah, M.K.M. (2021) A Mini Review on Natural Fiber Honeycomb (NFH) Sandwiched Structure Composite: Flexural Perfomance Perspective. Journal of Materials Science and Chemical Engineering, 9, 1-10.

https://doi.org/10.4236/msce.2021.95001

Received: April 14, 2021

Accepted: May 18, 2021

Published: May 21, 2021

Copyright $\odot 2021$ by author(s) and Scientific Research Publishing Inc. This work is licensed under the Creative Commons Attribution International License (CC BY 4.0).

http://creativecommons.org/licenses/by/4.0/

\begin{abstract}
Natural Fiber Honeycomb (NFH) sandwiched structure composite is a type of composite that uses natural fiber as the reinforcement material and honeycomb structure in the form of a sandwich panel. The demand for commercial use of natural fiber-based composites is increasing in the past few years in many industrial sectors. The increase in popularity of natural fibers is because of their particular properties, price, health benefits, and recyclability. This paper aims to analyze the data and analysis of the past research about $\mathrm{NFH}$ sandwiched structure composite in terms of the materials used to make the NFH, the physical and mechanical properties, and their applications. Based on the literature review conducted, there were many types of materials used to make the NFH sandwiched structure composite. Some experimental tests were planned and conducted to analyze the mechanical properties of the $\mathrm{NFH}$ and its potential to be used in the desired industries. However, there are not many implementations of NFH composite in the construction industry. This is due to the concern related to the issue of the structural integrity of the NFH composite. From the literature review conducted, most of the research shows a positive analysis of the mechanical properties and the potential of the developed NFH to be used for the targeted industry in the study. Therefore, it can be observed that the material used in this study has a high potential to be used in the construction industry.
\end{abstract}

\section{Keywords}

Natural Fiber Honeycomb, Flexural Performance, Sandwiched Structure Composite

\section{Introduction to NFH Production}

NFH materials have been widely applied as an important type of lightweight 
material in many industries, such as aerospace, automotive, and marine industry because of the reliable mechanical properties and very good designability [1]. Fiber-reinforced composites are the most effective way to build ultralight honeycomb materials with better mechanical properties. Fiber-reinforced composite honeycomb materials, which are lightweight and have superior mechanical properties, have drawn a lot of interest in recent years as a possible replacement for standard aluminium honeycombs and Nomex honeycombs [2]. Fiber-reinforced composites have a number of advantages over metal, polymer, and Nomex paper, including high specific stiffness and specific strength, good fatigue property, corrosion resistance, and high-temperature resistance [1] [2] [3] [4] [5]. As a result, the uses of fiber-reinforced honeycomb material for sandwich cores in hypersonic vehicles, long-range rockets, cargo vessels, and protective system are limitless [1].

NFH composite is a composite type that used natural fiber as the reinforcement material and honeycomb structure as the sandwich panel. According to reference [6], a new type of honeycomb core has been introduced, consists of a natural-fiber reinforced composite with a thermoset polymer (vinyl ester) reinforced with jute fabrics. Compression moulding was used to create $6 \mathrm{~mm}$ and 10 mm cell honeycombs using two moulds, one with fixed inserts and the other that enables lateral compression. A general-purpose vinyl ester resin was used to create the matrix material, Derakane Momentum 411-350 (Dow Chemical). Other than that, for the catalyst, with a weight ratio of 1:0.05, Methyl ethyl ketone peroxide (MEKP) was used. The reinforcement material for this project which is woven jute fabric is commercially available. For this project, it was supplied by Casthanal Textil CIA (Brazil) [6].

In another research, by reference [7], Haining Dingqiao Anbang Building Materials Factory (Haining, China) supplied the basalt fiber resin-based plate. The length of the basalt fiber is $13 \mu \mathrm{m}$. Easycompositites Company (Beijing, China) was the company that supplied the Phenolic resin. The phenolic resin was used to coat the honeycomb core with an inner diameter of $3.2 \mathrm{~mm}$ and 0.05 $\mathrm{mm}$ of wall thickness. For the adhesive, it was supplied by Dongguan HeiMa Chemical Co., Ltd., Dongguan, China. Epoxy resin was used as the adhesive which consists of $\mathrm{BH}-653$ water-borne epoxy emulsion and $\mathrm{BH}-519$ water-borne curing agent with 2:1 mixed volume ratio [7].

In a different study, by reference [8], a mixture of nonwoven fabrics consists of different jute/polypropylene (PP) fractions with jute/PP composite plates reinforced with jute/PP were used. Polyester (PET) foam, PP honeycomb, and balsa wood were used as core materials in this research (Figure 1). NaOH solution was used to treat the Jute/PP nonwoven fabrics before sandwich preparation to enhance the fiber matrix's adhesion and strength of the facing-core bonding. The fabric received from the Department of Textile Technology, Indian Institute Technology, and Delhi, India. The fabrics are made of Bangla Tossa C grade jute fibers with a density of $1.42 \mathrm{~g} / \mathrm{cm}^{3}$ [8]. 


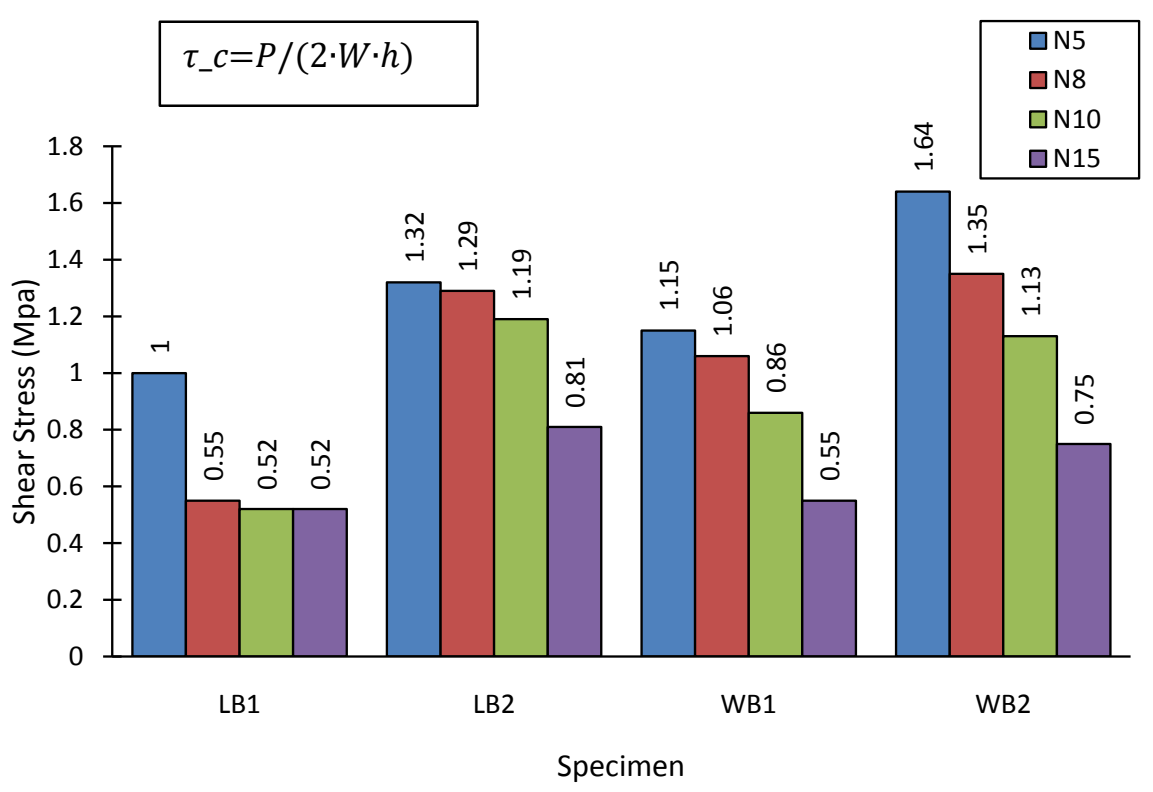

Figure 1. Graph of shear stress of samples from reference [7].

Other than that, a study by reference [9] developed honeycomb cores by compression molding using a home-made aluminum mold while the reinforcement fibers used were the flax fibers supplied by Safilin as untreated Tex 5000 low-twist strands. The matrix consists of an 820 epoxy/824 hardener solution supplied by Adtech Plastic and combined with an 18/100 hardener/resin ratio as suggested by the supplier [9].

There are already applications of sandwiched structure composites in other industry however the usage of NFH in the construction industry should be developed further. Therefore, this study will benefit the targeted industry as it will introduce the application of NFH which is a more environmentally product to the industry. This review is expected to contribute to a new perspective about NFH usage in construction industry from a flexural performance perspective.

\section{Flexural Performance of NFH}

The flexural performance of NFH is usually carried out by conducting flexural test. This test is a form of experiment which measures the force needed to bend a material which is in the shape of a beam under three-point loading conditions. According to reference [10] and [11], the most common test method to evaluate the flexural performance of a material is by performing the three-point bending test. In order to find a suitable material for structural application, the flexural load, flexural modulus, and deflection at the point of the material breaks are needed to be determined [10] [11]. It was further emphasized that studying the flexural properties of natural fiber composites, the relationship between fiber quality or fiber length and flexural strength could be found out [11]. Apart from the relationship of fiber quality and flexural strength, the load increments, the maximum strain and maximum fiber stress are also could be found out from 
this study. According to reference [11], the flexural modulus of the material also can be obtained from the results of the slope on the stress against deflection curve [12].

Reference [7] carried out a flexural test by using a three-point bending test on the structure of an NFH composite. Two different standard was used to perform the flexural test which are the Chinese standard test method (GB/T 1453) for the sandwich construction's flexural properties and American Standard Test Method (ASTM) C393 for the core shear properties of sandwich construction. Two different specimen shape was used which are L-shaped and $\mathrm{W}$-shaped, in order to analyze the bending capacity of two different shape. It was believed that there are three key factors influence flexure properties which are the sheet's thickness, the height of the honeycomb, and the honeycomb orientation. Among them, the thickness of the sheet has the most significant effect on the flexural properties [7].

The results (depicted in Figure 1) concluded that by increasing the fiber sheets' thickness in the same height and direction, the core shear stress could be effectively increased. The bigger the honeycomb thickness ratio, the higher the possibility of the honeycomb wall to yield during the bending process, minimize the honeycomb core's shear stress. Having similar height of honeycomb and similar sheet thickness, the W-shaped sample has a higher shear stress than the L-shaped sample. Reference [7] further explained that bonding layer breaks between the sheet and the core honeycomb wall in the bending process, which decreases the shear stress of the honeycomb core [7].

Based on Figure 2, the position honeycomb was also found to affect the flexure stiffness of the composite structure. Reference [7] further stressed that the increase in the fiber sheet thickness will significantly boost the flexural stiffness of the structure, with a highest increase of 323\%, although increasing the honeycomb height will not give big impact on the flexural stiffness of the structure. The flexure strength and core shear stress of the $\mathrm{W}$-shaped sample are more significant than that of the L-shaped sample and do not affect the sample's flexure stiffness. This study proves that the flexural strength of a sandwiched structure composite is affected by the height and thickness of the honeycomb [7].

Apart from that, the direction of the honeycomb also has effect on the sample's flexural stiffness. The study in reference [8] indicates that different factors affect the mechanical properties of NFH. A three-point bending test was used in their study on the flexural behavior of NFH of a sandwich composite structure similar to reference [7], except, reference [8] incorporated Euler-Bernoulli and Timoshenko beam theories. Three-point flexural tests were carried out in Zwick/Roell-Z010 universal machine with a $10 \mathrm{kN}$ times force load cell following ASTM C 393. Figure 3 below shows the flexural strength against jute fiber volume fraction ratio inside the sandwich composite. The significance of the results was tested with analysis of variance (ANOVA). Due to the reinforcing effect of jute fibres and the beneficial effect of hybridization, the flexural strength 
$D=\left(l^{\wedge} 2 \cdot a \cdot \Delta P\right) /\left(16 f_{-} 1\right)$

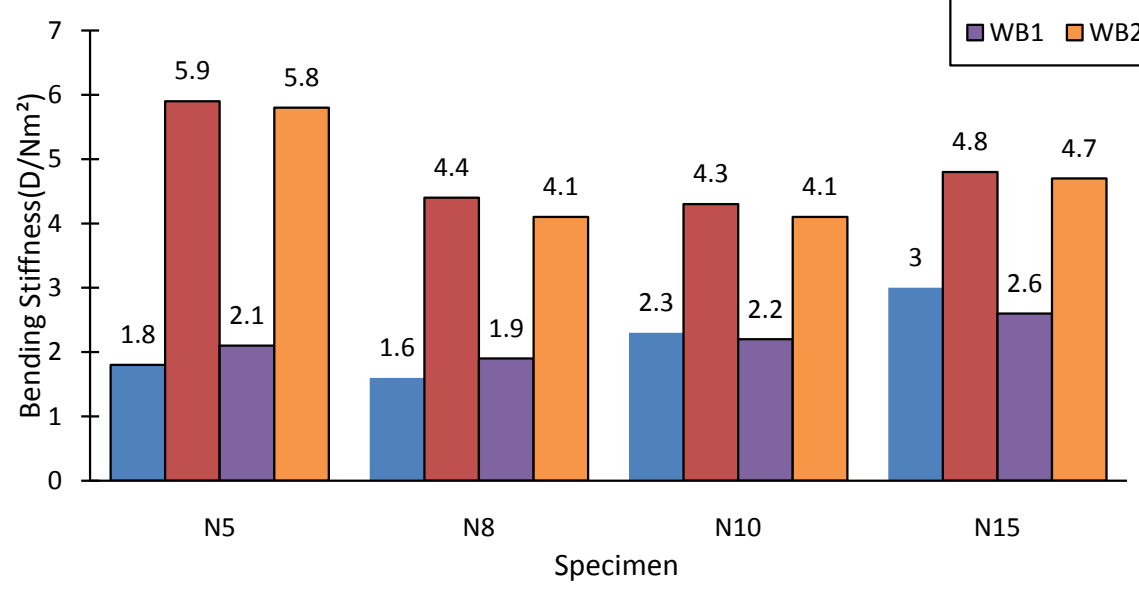

Figure 2. Flexure stiffness comparison of the bending samples from reference [7].

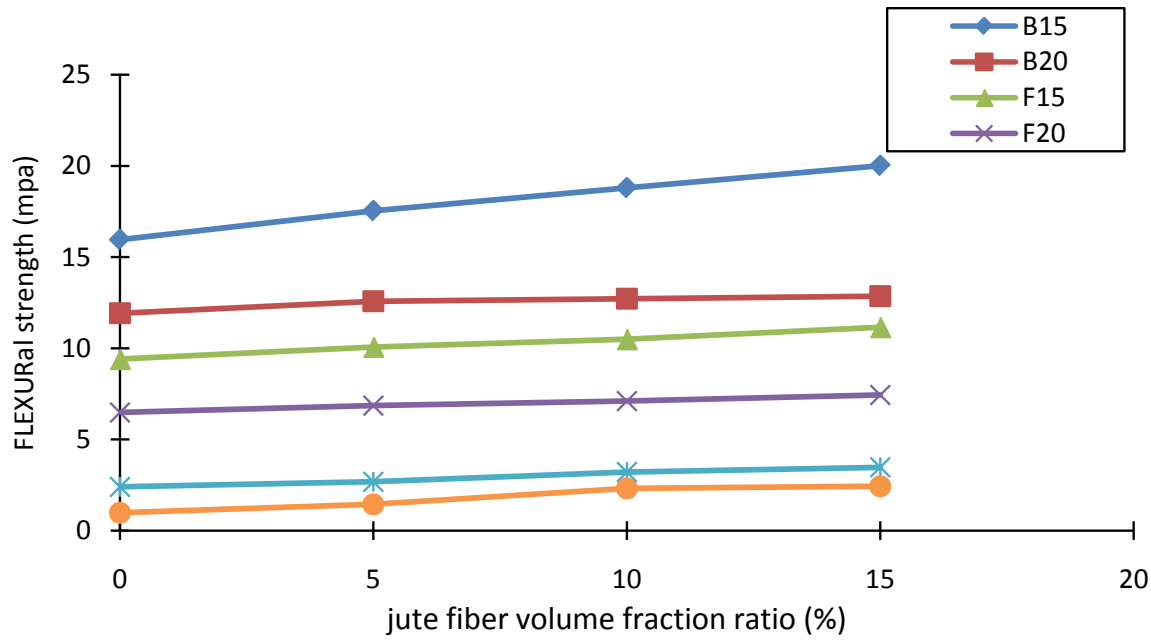

Figure 3. Graph of flexural strength against jute fiber volume fraction ratio of the sandwiches from reference [8].

of the mixture of $10 \%$ and $15 \%$ jute fibre in the samples was improved. However, there was no substantial change that can be seen for the 5\% jute fibre content. For all sandwich specimens, the flexural strength of PET foam-coated sandwiches increased as the fibre loading increased, excluding the specimen with the lowest jute content (J5-F15), according to ANOVA findings. Correspondingly, the inclusion of jute fibres increased the flexural strength of PP honeycomb sandwiches for all jute fibre contents [8].

The difference in flexural modulus of sandwich samples with jute fiber content is seen in Figure 4 below. Except for thin sandwich specimen with 5\% jute fiber content, the flexural modulus of the specimens increased with the addition of jute fiber. The conclusion of the research shows that the jute fiber loading increased the rigidity, flexural strength, and flexural modulus of the sandwiches [8]. 


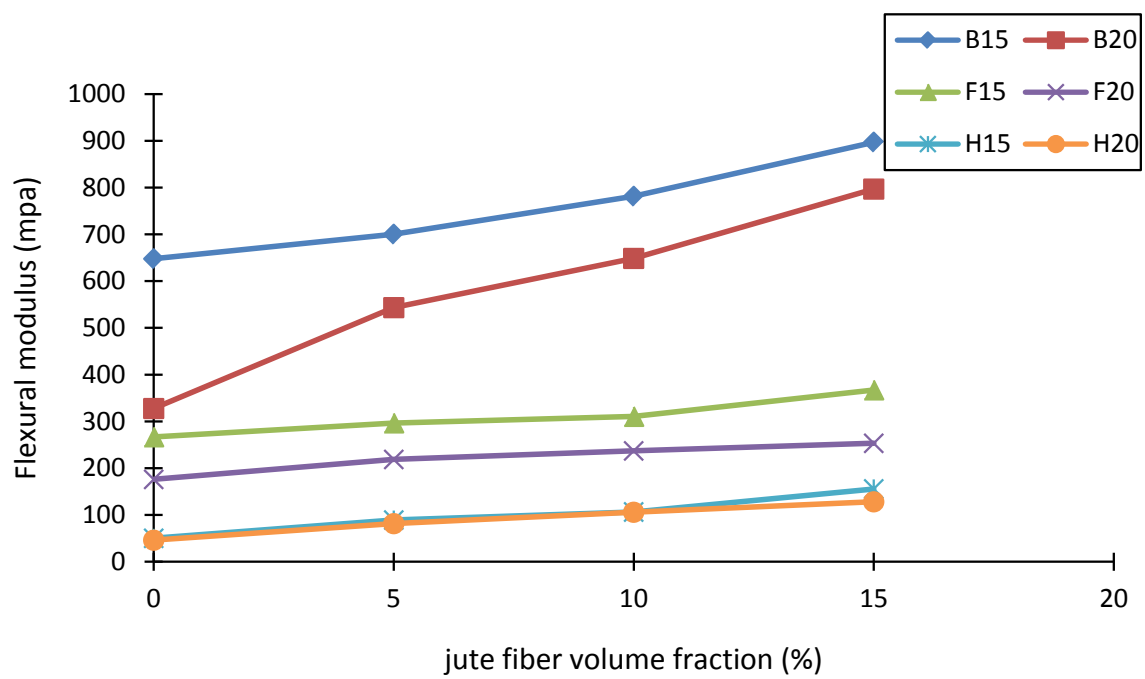

Figure 4. Graph of flexural modulus against jute fiber volume fraction ratio of the sandwiches from reference [8].

Another conclusion that was drawn by reference [8] was that as the core thickness increased, the flexural strength and modulus of the sandwiches reduced. This statement, however, contradicts with the conclusion of reference [7]. According to reference [8], the effect of the increase in the volume fraction of the core material on the sandwich's global flexural properties is quite low. However, research in reference [13] found to have consistent results with reference [8] in their review of paper/epoxy facing-aramid honeycomb core sandwiches, where it was evident that the sandwiches' flexural strength and modulus decreased as the core's thickness increased. The decrease in flexural strength and modulus was attributed to a rise in the core's material volume fraction, according to references [13] and [8]. Before entering the plastic area, all samples showed linear activity at low loading levels. The samples then showed no signs of brittleness. With the use of jute fibers, the stiffness of the composites increased. The Euler-Bernoulli model recorded lower deflection values than experimental findings, while the Timoshenko model gave a fair estimate of the sandwich's flexural properties. This result suggested that, when using these materials for a particular application, shear deflections must be considered. Overall, this study interprets that the combination of natural fiber and honeycomb core improved the flexural properties of the sandwiches [8] [13].

However, another study in reference [14] shows another outcome where the flexural test was performed by using the three-point bending test on the honeycomb core. The core was constructed from a natural-fiber reinforced composite composed of epoxy resin reinforced with jute fiber. $6 \mathrm{~mm}$ hexagonal and $6 \mathrm{~mm}$ diameter circular cores were manufactured using compression molding technique as shown in Figure 5 below. The three-point bending test was conducted following the ASTM D 790 standard using an Instron 4467 machine to determine the flexural strength of the composites. From Table 1 below, it can be 


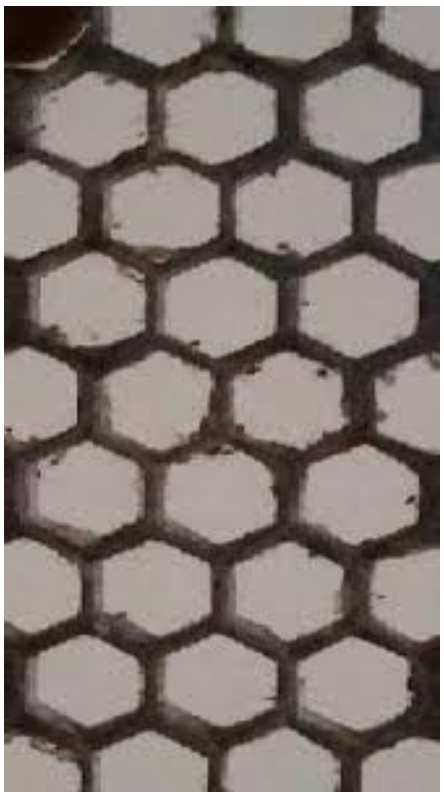

(a)

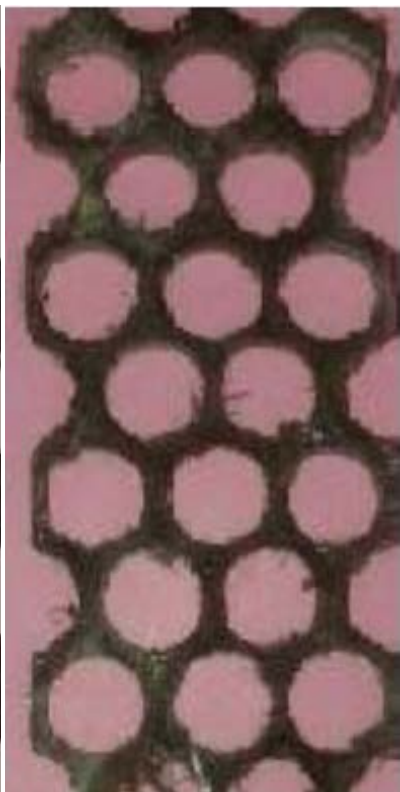

(b)

Figure 5. (a) jute fiber reinforced honeycomb core (b) jute fiber reinforced circular core from reference [14].

Table 1. Comparison of circular core vs hexagonal core from reference [14].

\begin{tabular}{cccccc}
\hline & \multicolumn{2}{c}{ Circular Core } & \multicolumn{2}{c}{ Hexagonal Core } & \\
\hline Sample No. & $\begin{array}{c}\text { Flexural } \\
\text { Strength (MPa) }\end{array}$ & $\begin{array}{c}\text { Flexural } \\
\text { Strain (\%) }\end{array}$ & $\begin{array}{c}\text { Flexural } \\
\text { Strength (MPa) }\end{array}$ & $\begin{array}{c}\text { Flexural } \\
\text { Strain (\%) }\end{array}$ & $\begin{array}{c}\text { Specimen } \\
\text { Behaviour }\end{array}$ \\
\hline $\mathbf{1}$ & 9.23 & 4.17 & 7.03 & 3.19 & Yield \\
$\mathbf{2}$ & 7.10 & 3.22 & 6.16 & 3.10 & Yield \\
$\mathbf{3}$ & 6.52 & 3.01 & 6.03 & 2.96 & Yield \\
$\mathbf{4}$ & 6.43 & 2.65 & 6.10 & 2.48 & Yield \\
$\mathbf{5}$ & 5.85 & 2.47 & 5.06 & 2.13 & Yield \\
Mean & 7.00 & 3.10 & 5.48 & 2.77 & \\
S.D. & 1.09 & 0.59 & 0.58 & 0.72 & \\
\hline
\end{tabular}

observed that the average flexural strength of the circular core and hexagonal core were $7 \mathrm{MPa}$ and $5.48 \mathrm{MPa}$ respectively. This result suggests that jute fiber reinforced circular core exhibit higher flexural strength compared to jute fiber reinforced hexagonal (honeycomb) core [14].

\section{NFH as Construction Material for Building Application}

Currently in the construction industry, reinforced concrete (RC) panels are widely used for the construction of floors in residential buildings, industrial buildings, bridge decks, and other structures. In order to reduce construction time, slabs can be prefabricated and delivered to construction sites to shorten construction time, or they can be built on-site [15] [16]. However, for NFH, only 
Table 2. Flexural strength of CFRP from reference [15].

\begin{tabular}{cccc}
\hline Panel Size $(\mathrm{mm})$ (width $\times$ length) & Slab Number & Load, $P(\mathrm{kN})$ & Flexural Strength, $\mathrm{f}(\mathrm{MPa})$ \\
\hline \multirow{2}{*}{$\mathbf{1 6 0 \times 1 6 0}$} & 1 & 45.00 & 8.49 \\
& 2 & 47.00 & 9.01 \\
$\mathbf{2 3 0} \mathbf{2 3 0}$ & 3 & 49.88 & 9.33 \\
& 1 & 44.60 & 8.45 \\
& 2 & 46.89 & 8.47 \\
$\mathbf{3 2 0} \times \mathbf{3 2 0}$ & 3 & 48.89 & 9.16 \\
& 1 & 42.23 & 7.71 \\
& 2 & 43.82 & 8.28 \\
& 3 & 47.50 & 9.24
\end{tabular}

a few research or studies have been reported on the structural behaviour but those studies do not indicate the potential of using NFH in construction industry. Given the flexural strength of using RC panel to be deemed as safe to be used as flooring material [15], based on the review discussed above, NFH also exhibits similar flexural strength as RC panels.

Reference [15] conducted research to compare the flexural strength of RC panel and cement fiber reinforcement panel (CFRP). However, as opposed to the usual 3 point bending test, reference [15] used a 4 point bending test. Table 2 shows the result of flexural strength of CFRP according to reference [15]. By comparing to the result of flexural test in Table 2 and results from reference [8] and reference [14] who have obtained a flexural strength of maximum $18 \mathrm{MPa}$ by using a mixture of jute fiber and PP and $7 \mathrm{MPa}$ by using jute fiber and epoxy resin respectively, it is safe to deduce that replacing NFH with conventional building material is possible. However, more studies are required in order to confirm the structural integrity whether using NFH as building material is really suitable to replace the conventional building material.

\section{Conclusion}

Based on the short review performed, there are already many researchers who developed NFH by using materials like aluminum, Nomex, and plastic. Taking aluminum as an example, it has been mainly used as a face sheet. However, this type of face sheet can bend over time which is not ideal to be used as a flooring panel. Besides that, there are already applications of sandwiched structure composites in other industry however the usage of NFH in the construction industry should be developed further. Based on the flexural capability of NFH, it is evident that NFH has the potential to be used as building materials especially as flooring panels as it is comparatively the same or even much better than conventional building materials such as concrete or reinforced concrete. It is also expected to be cheaper in cost, lightweight, and easy to install compared to conventional construction material. However, further research is required for NFH 
in order to be qualified as construction materials such as fire withstand capability, moisture absorption, and health effects. One of the challenges of implementing this material as a construction material that was identified from this review is the flexural performance of the material as the material ages over time. The concern is whether the material will become weak or fragile over time as it will potentially pose a threat to the structural integrity of the material. Another potential challenge is the flexural performance of the structure as the adhesive material becomes less effective over time. This concerns the debonding of the facesheet from the core which also can be a threat to the structural integrity.

\section{Acknowledgements}

The author would like to thank the whole research team who were involved in this research. On behalf of the Advance Composite Group, the author would like to thank Universiti Malaysia Sabah for providing the opportunity, funding and platform for this research to take place.

\section{Conflicts of Interest}

The authors declare no conflicts of interest regarding the publication of this paper.

\section{References}

[1] Wei, X., Xiong, J., Wang, J. and Xu, W. (2020) New Advances in Fiber-Reinforced Composite Honeycomb Materials. Science China Technological Sciences, 63, 1348 1370. https://doi.org/10.1007/s11431-020-1650-9

[2] Birman, V. and Kardomateas, G. (2018) Review of Current Trends in Research and applications of Sandwich Structures. Composites Part B: Engineering, 142, 221-240. https://doi.org/10.1016/j.compositesb.2018.01.027

[3] Baggetto, L., Danilov, D. and Notten, P. (2011) Honeycomb-Structured Silicon: Remarkable Morphological Changes Induced by Electrochemical (De) Lithiation. Advanced Materials, 23, 1563-1566. https://doi.org/10.1002/adma.201003665

[4] Yuan, Z. and Shi, J. (2010) Research on EM Pulse Protection Property of PlasmaMicrowave Absorptive Material-Plasma Sandwich Structure. Science China Technological Sciences, 53, 3221-3224. https://doi.org/10.1007/s11431-010-4159-1

[5] Zhuang, J., Xu, X., Feng, H., Li, Z., Wang, X. and Du, Y. (2015) Honeycomb Silicon: a Review of Silicene. Science Bulletin, 60, 1551-1562. https://doi.org/10.1007/s11434-015-0880-2

[6] Stocchi, A., Colabella, L., Cisilino, A. and Álvarez, V. (2014) Manufacturing and Testing of a Sandwich Panel Honeycomb Core Reinforced with Natural-Fiber Fabrics. Materials \& Design, 55, 394-403. https://doi.org/10.1016/j.matdes.2013.09.054

[7] Li, Z. and Ma, J. (2020) Experimental Study on Mechanical Properties of the Sandwich Composite Structure Reinforced by Basalt Fiber and Nomex Honeycomb. Materials 2020, 13, Article No. 1870. https://doi.org/10.3390/ma13081870

[8] Karaduman, Y. and Onal, L. (2016) Flexural Behavior of Commingled Jute/Polypropylene Nonwoven Fabric Reinforced Sandwich Composites. Composites Part B: Engineering, 93, 12-25. https://doi.org/10.1016/j.compositesb.2016.02.055

[9] Selmi, S., Habibi, M., Laperrière, L. and Kelouwani, S. (2020) Characterisation of 
Natural Flax Fibers Honeycomb: Compression Damage Analysis Using Acoustic Emission. Journal of Natural Fibers, 1-10. https://doi.org/10.1080/15440478.2020.1789531

[10] Imoisili, P.E., Ukoba, K.O., Attahdaniel, E. and Olusunle, S.O.O. (2020) Development of 3-Point Flexural Test Fixtures. Innovative Systems Design and Engineering, 5, 56-59.

[11] Sathishkumar, T.P. and Navaneethakrishnan, P. (2012) Tensile and flexural properties of Snake Grass Natural Fiber Reinforced Isophthallic Polyester Composites. Composite Science Technology, 72, 1183-1190.

https://doi.org/10.1016/j.compscitech.2012.04.001

[12] SatishKumar, P., Neethimanickam, I.R., Robinston, J.S. and Maheswari, K.S. (2020) Strength and Behavior Analysis Of Honey Comb Sandwich Composite Structure. International Journal of Scientific \& Technology Research, 9, 2669.

[13] Du, Y., Yan, N. and Kortschot, M.T. (2012) Light-Weight Honeycomb Core Sandwich Panels Containing Biofiber-Reinforced Thermoset Polymer Composite Skins: Fabrication and Evaluation. Composites Part B: Engineering, 43, 2875-2882.

https://doi.org/10.1016/j.compositesb.2012.04.052

[14] Arora, S.P.S. and James, N.R. (2016) Study the Effect of Core Design on Mechanical Behaviour of Honeycomb Sandwich Structures under Three Point Bending. International Journal of Innovative Research in Science, Engineering and Technology, 5, 9444-9449.

[15] Aman, S.S., Mohammed, B., Wahab, M. and Anwar, A. (2020) Performance of Reinforced Concrete Slab with Opening Strengthened Using CFRP. Fibers, 8, Article No. 25. https://doi.org/10.3390/fib8040025

[16] Anwar, A., Mohammed, B., Liew, M., Wahab, M. and Zawawi, N. (2019) Below-Grade Sulfur Storage Pits in Oil Refineries: A Review. Journal of Failure Analysis and Prevention, 19, 1745-1760. https://doi.org/10.1007/s11668-019-00773-0 